\title{
Poesia brasileira e ditadura: memória e desaparecimento em Ricardo Domeneck, Eduardo Sterzi, Paulo Ferraz e Priscila Figueiredo
}

\author{
Brazilian poetry and dictatorship: memory and disappearance in Ricardo \\ Domeneck, Eduardo Sterzi, Paulo Ferraz and Priscila Figueiredo \\ Poesía brasileña y dictadura: memoria y desaparición en Ricardo Domeneck, \\ Eduardo Sterzi, Paulo Ferraz y Priscila Figueiredo
}

\section{Pádua Fernandes}

paduafernandes@gmail.com

Instituto de Pesquisa Direitos e Movimentos Sociais

(IPDMS), Brasil

Recepção: 08 Outubro 2020

Aprovação: 25 Outubro 2020

Publicación: 01 Dezembro 2020

Cita sugerida: Fernandes, P. (2020). Poesia brasileira e ditadura: memória e desaparecimento em Ricardo Domeneck, Eduardo Sterzi, Paulo Ferraz e Priscila Figueiredo. Aletheia, 11(21), e065. https://doi.org/10.24215/18533701e065
Resumo: O artigo analisa poemas de Ricardo Domeneck, Eduardo Sterzi, Paulo Ferraz e Priscila Figueiredo, que tratam de questões sobre graves violações de direitos humanos cometidas pelo Estado brasileiro, como a memória dos desaparecidos ou das vítimas da ditadura militar. A análise enquadra-se no campo da literatura e justiça de transição, com o objetivo de estudar o cruzamento entre invenção literária e memória social, no tocante ao legado dos crimes contra a humanidade praticados pelo Estado brasileiro. Todos esses autores nasceram nos anos 1970, durante a ditadura militar no Brasil, que durou de 1964 a 1985. Os poemas analisados foram escritos no século XXI, em um novo ciclo de memória cultural no Brasil, segundo a hipótese de Rebecca Atencio, no qual os temas ligados à ditadura voltaram a ser objeto da literatura brasileira com mais frequência. No caso de Paulo Ferraz, o poema diz respeito à Era Vargas (1930-1945). Domeneck, cujo poema é mencionado no relatório da Comissão Nacional da Verdade, e Sterzi referemse à ditadura militar. Priscila Figueiredo trata das continuidades do passado autoritário nos crimes do Estado brasileiro após a democratização. Nesses quatro casos, a poética desses autores difere da que argentinos reunidos sob a categoria dos "hijos" têm estabelecido.

Palavras-chave: Poesia brasileira contemporânea, Literatura e política, Justiça de transição, Ditadura militar, Memória.

Abstract: The article analyzes poems by Ricardo Domeneck, Eduardo Sterzi, Paulo Ferraz and Priscila Figueiredo, which deal with questions about serious human rights violations committed by the Brazilian State, as the memory of the disappeared or the victims of the military dictatorship. The analysis fits in the field of literature and transitional justice, with the aim of studying the intersection between literary invention and social memory, with regard to the legacy of crimes against humanity practiced by the Brazilian State. All of these authors were born in the 1970s, during the military dictatorship in Brazil, which lasted from 1964 to 1985. The analyzed poems were written in the 21 st century, in a new cycle 
of cultural memory in Brazil, according to the hypothesis of Rebecca Atencio, in which themes related to the dictatorship returned to be the object of Brazilian literature more frequently. In the case of Paulo Ferraz, the poem concerns the Vargas Era (1930-1945). Domeneck, whose poem is mentioned in the report of the National Truth Commission, and Sterzi refer to the military dictatorship. Priscila Figueiredo deals with the continuities of the authoritarian past in the crimes of the Brazilian State after democratization. In these four cases, the poetry of these authors differs from that which Argentines gathered under the category of "hijos" have established.

Keywords: Contemporary Brazilian poetry, Literature and politics, Transitional justice, Military dictatorship, Memory.

Resumen: El artículo analiza poemas de Ricardo Domeneck, Eduardo Sterzi, Paulo Ferraz y Priscila Figueiredo, que tratan cuestiones sobre graves violaciones de derechos humanos cometidas por el Estado brasileño, como la memoria de los desaparecidos o las víctimas de la dictadura militar. El análisis se inscribe en el campo de la literatura y la justicia transicional, con el objetivo de estudiar la intersección entre invención literaria y memoria social, en relación con el legado de crímenes de lesa humanidad practicados por el Estado brasileño. Todos estos autores nacieron en la década de 1970, durante la dictadura militar en Brasil, que duró de 1964 a 1985. Los poemas analizados fueron escritos en el siglo XXI, en un nuevo ciclo de memoria cultural en Brasil, según la hipótesis de Rebecca Atencio, en la que los temas relacionados con la dictadura volvieron a ser objeto de la literatura brasileña con mayor frecuencia. En el caso de Paulo Ferraz, el poema se refiere a la Era Vargas (1930-1945). Domeneck, cuyo poema se menciona en el informe de la Comisión Nacional de la Verdad, y Sterzi se refieren a la dictadura militar. Priscila Figueiredo se ocupa de las continuidades del pasado autoritario en los crímenes del Estado brasileño tras la democratización. En estos cuatro casos, la poesía de estos autores difiere de la que han establecido los argentinos reunidos en la categoría de "hijos".

Palabras clave: Poesía brasileña contemporánea, Literatura y política, Justicia transicional, Dictadura militar, Memoria.

\section{INTRODUÇÃO: A DITADURA E A POESIA BRASILEIRA CONTEMPORÂNEA}

A maior parte dos trabalhos sobre a literatura brasileira do século XXI e a ditadura militar deixou de lado a poesia. No recente inventário sobre o assunto, A literatura como arquivo da ditadura brasileira, de Eurídice Figueiredo (Figueiredo, 2017), o gênero foi deixado de lado e todos os autores mais jovens analisados aparecem apenas por suas obras de prosa de ficção sobre temas relacionados à ditadura militar. $\mathrm{O}$ importante livro de Rebecca Atencio, Memory's Turn(Atencio, 2014), ao trazer a hipótese do surgimento de um novo ciclo de memória cultural no Brasil no século XXI, com a retomada daqueles temas, abordou o cinema, a televisão, $\mathrm{o}$ teatro mas, na literatura, deixou de lado a poesia. 
A ditadura militar atacou, desde 1964, a literatura, as artes e a edição. Os militares, com fundamento na versão brasileira da doutrina de segurança nacional, viam o campo das artes como uma área propícia a certo tipo de subversão, a que chamavam de "guerra psicológica". Já em 1959, em curso da Escola Superior de Guerra (ESG), "Introdução ao estudo da guerra revolucionária”, ministrado pelo então Coronel Augusto Fragoso, dizia-se que a "Guerra Revolucionária" (GR) tem “aspecto de guerra civil, guerra interna” e "é, antes de tudo, ideológica. Ela exclui, salvo caso de extrema necessidade, a guerra militar clássica -atômica ou nãocomo fator principal da decisão, e reconhece a luta psicológica como modo de ação essencial e permanente" (Escola Superior de Guerra, 1959, p. 2).

Essa definição foi institucionalizada, depois do golpe de 1964, na legislação de segurança nacional ${ }^{1}$. Persistiriam durante todo o regime as ideias do inimigo interno subversivo e de uma guerra revolucionária presente, de caráter ideológico ou psicológico (agitprop), que serviam como justificativa oficial para a censura às liberdades de pensamento, de expressão e de imprensa e o cerceamento às manifestações públicas.

Símbolo disso, em 1o de abril de 1964, foi a invasão e a depredação do prédio do Instituto Superior de Estudos Brasileiros (ISEB), logo extinto pelo governo ditatorial pelo Decreto $\mathrm{n}^{\circ} 53.884$ de 13 de abril de 1964; todos seus professores tiveram que responder a inquérito penal militar (Abreu, 2009). O Instituto publicava, com o CPC (Centro Popular de Cultura) da UNE (União Nacional dos Estudantes) e a editora Civilização Brasileira a coleção Cadernos do Povo Brasileiro, de que foram números especiais, em 1962 e 1963 , os três volumes de poesia Violão de Rua - Poemas para a liberdade(Lovatto, 2013).

Também em abril de 1964, a ditadura invadiu o Movimento de Cultura Popular, no Recife, que contava com diversos intelectuais (como Luiz Costa Lima e Paulo Freire) e artistas: "Prisões de vários dos seus integrantes foram realizadas, como as de Germano Coelho, Paulo Freire, Anita Paes Barreto, do escultor militante e dirigente do PCB Abelardo da Hora, Joacir de Castro, Luiz Costa Lima, Jomard Muniz de Brito, entre outros." (Comissão Estadual da Verdade Dom Helder Câmara, 2017, vol. II, pp. 244-245). Nesses casos, o governo aplicou a estratégia de cortar "as pontes entre o movimento cultural e as massas" (Schwarz, 1978, p. 62).

A literatura engajada dessa época foi criticada por sua instrumentalização a serviço de causas políticas, em geral de intelectuais ligados ao PCB (Ridenti, 2000). Ferreira Gullar criticava a própria produção dessa época, em que participava do CPC, nestes termos: "Eu não estava fazendo literatura, mas política." (Jiménez, 2013, p. 157).

A produção poética, nos anos 1970, mudou de rumo, da "proposta global da opção alternativa" à "ordem do sistema", para caminhos diversos da literatura engajada dos anos 1960, com os poetas da chamada geração marginal (Holanda, 1980, p. 99). Novos caminhos de escrita surgiram, e o que Cacaso, um desses novos nomes, escreveu sobre seu contemporâneo Chacal vale para boa parte dessa geração: "uma alergia visceral relativamente à situação e ao clima de autoritarismo reinante de alto a baixo no país, dentro e fora da vida literária." (Cacaso, 1997, p. 43).

No entanto, a ditadura militar logo deixaria de ser um assunto importante para a maior parte dos autores a partir do fim dos anos 1980. Aparentemente refletindo um movimento maior na sociedade brasileira de soterrar as questões de justiça, memória e verdade, os escritores aparentemente deram o assunto por resolvido. As graves violações de direitos humanos da ditadura militar brasileira, porém, não haviam sido apuradas, muito menos punidas; os desaparecidos não haviam sido encontrados; não havia sido estimado o número de vítimas de genocídio entre os povos indígenas.

$\mathrm{Na}$ democratização do país não se realizou a justiça de transição, ou seja, a partir dos eixos definidos pela Organização das Nações Unidas, o "conjunto de medidas, após certo Estado sair de conflitos ou de regimes autoritários, para apuração e sanção de graves violações de direitos humanos, iniciativas de memória everdade, de reparação aos atingidos e de reforma das instituições" (Fernandes, 2019, p. 2).

Nos dois mandatos do presidente Fernando Henrique Cardoso (1995-2002) foram possíveis alguns avanços, como a aprovação da lei dos desaparecidos políticos, de 1995, que instituiu a Comissão Especial 
de Mortos e Desaparecidos Políticos (CEMDP). Já no governo Lula, as Conferências Nacionais de Direitos Humanos foram importantes para a definição de um eixo de memória e verdade.

Rebecca Atencio (2014) sustenta que nessa época formou-se um novo ciclo de memória cultural no Brasil. Em Memory's Turn, ela aponta como obra literária desse novo ciclo o romance de Fernando Bonassi Prova contrária (2003), que parte da experiência da CEMDP para criar um personagem de falso desaparecido. De fato, apenas no século XXI surge, depois de muita discussão política e a condenação do Estado brasileiro pela Corte Interamericana de Direitos Humanos no caso da Guerrilha Araguaia (caso Gomes Lund e Outros vs. Brasil, movido pela Comissão de Familiares de Mortos e Desaparecidos Políticos), a Comissão Nacional da Verdade, instituída em 2012, no governo de Dilma Rousseff.

Ricardo Domeneck escreveu que apenas neste século a literatura brasileira contemporânea voltou a tratar do período (Domeneck, 2014), o que se coaduna com a hipótese de Atencio sobre o novo ciclo de memória cultural. Neste artigo, além do próprio Ricardo Domeneck (nascido em Bebedouro, no interior do Estado de São Paulo, em 1979), analisaremos poemas de Eduardo Sterzi (Porto Alegre, 1973), Priscila Figueiredo (São Paulo, 1973) e Paulo Ferraz (Rondonópolis, 1974), que teriam a idade compatível a uma geração de "H.I.J.O.S." no Brasil (a última ditadura tendo começado em 1964).

Os poemas de Domeneck e Sterzi foram publicados originalmente antes da instalação da Comissão Nacional da Verdade (CNV), em 2012, período em que as questões de memória, verdade e justiça sobre a ditadura já eram discutidas publicamente com renovada polêmica. Os de Ferraz e Figueiredo foram publicados depois da publicação do relatório final da CNV, que ocorreu em dezembro de 2014.

\section{Uma desaparecida Política E UM NÃO-Monumento de Ricardo Domeneck}

O livro Medir com as próprias mãos a febre(Domeneck, 2015) foi lançado no ano seguinte à publicação do relatório da Comissão Nacional da Verdade (CNV). No entanto, o poema "sis Dias de Oliveira (1941 - ?)", nele recolhido, e citado pelo relatório da $\mathrm{CNV}$, havia sido publicado três anos antes, na data de aniversário do golpe de 1964, o lo de abril.

Izis Dias de Oliveira nasceu em 1941, em São Paulo, e desapareceu em 1972, quando foi presa e levada ao DOI-Codi do Rio de Janeiro. Estudou Ciências Sociais na Universidade de São Paulo, militou na ALN, a Ação Libertadora Nacional, e recebeu treinamento de guerrilha em Cuba. Sua história foi incluída no Dossiê dos mortos e desaparecidos politicos a partir de 1964, elaborado pela Comissão de Familiares de Mortos e Desaparecidos Políticos (uma organização da sociedade civil) e pelo Instituto de Estudos sobre Violência do Estado, desde sua primeira edição, de 1995. Esse dossiê, revisto e muito ampliado em 2009, serviu de base informal para os trabalhos da Comissão Nacional da Verdade. Oliveira também foi incluída no anexo da lei federal no 9.140 de 4 de dezembro de 1995 como um dos desaparecidos oficialmente reconhecidos pelo Estado brasileiro.

Domeneck publicou o poema em seu blogue (Rocirda Demencock) em $1^{\circ}$ de abril de 2012. Ele foi citado em campanhas na internet pela apuração e responsabilização dos crimes da ditadura (na rede "Desarquivando o Brasil"2). Em 2013, foi publicado em uma coletânea alemã de seus poemas, Körper: ein Handbuch, e também traduzido para o hebraico (Domeneck, 2013). Por fim, recebeu menção no relatório da Comissão Nacional da Verdade, publicado em dezembro de 2014, como uma das medidas de memória relativas a esta desaparecida:

Em 11 de setembro de 1997, o bairro paulistano da Lapa homenageou Izis batizando a praça situada em frente à residência onde a desaparecida viveu parte da vida ao lado de sua família. Os bairros Recreio dos Bandeirantes, no Rio de Janeiro, e o da Macaxeira, em Recife, também têm ruas que recebem o nome de Izis. No dia 7 de novembro de 2012, o Centro Acadêmico do curso de Ciências Sociais da USP, ao comemorar seus 55 anos de existência, celebrou a data batizando a entidade com o nome de Iziz Dias de Oliveira, em cerimônia ocorrida no prédio do curso, da qual participaram Dimas Dias de Oliveira, seu irmão, 
e José Luiz Del Roio, seu ex-marido. Em 1o de abril de 2012, Ricardo Domeneck lançou um poema com o nome de Izis, celebrando a data que rememora os 48 anos do golpe de Estado (Comissão Nacional da Verdade, 2014, volume III, p. 831).

No perfil, a CNV explica que adotou a grafia com a letra "z" porque dessa forma o nome havia sido registrado na certidão de nascimento. No Dossiê Ditadura: Mortos e desaparecidos políticos do Brasil 1964-1985, adotou-se a mesma grafia que o poeta empregou (Comissão de Familiares de Mortos e Desaparecidos Políticos, Instituto de Estudos sobre a Violência do Estado, 2009, p. 314).

A estrutura do poema é simples: composto de versos livres, em geral curtos e brancos (com algumas rimas toantes), apoia-se na repetição da palavra talvez, às vezes em anáfora. $\mathrm{O}$ poema compõe-se de fabulações a respeito da vida da personagem-título, se ela não tivesse desaparecido, o que inclui de banalidades cotidianas até a possibilidade de um suicídio (Domeneck, 2015, p. 27):

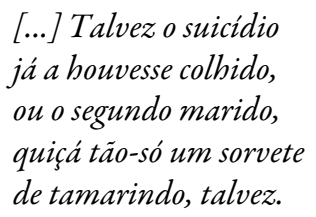

O tom do poema é não celebratório e antimonumentalizante. Ocorrem uma menção genérica à "luta" e outra explícita à guerrilha (Domeneck, 2015, p. 27-28):

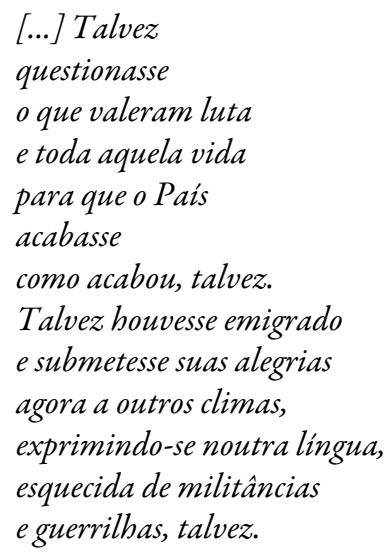

O poema não trata dos acontecimentos da guerrilha, que não é heroicizada (ele chega a imaginar que a militante a poderia ter esquecido no exílio), tampouco se refere diretamente à repressão política ou tenta imaginar a cena da prisão. No entanto, o desaparecimento todo o tempo está lá, na marca do "talvez": as eventuais histórias estão suspensas, o que indica não só a distância do eu lírico em relação à personagem, mas também a suspensão do futuro e do luto, própria do crime de desaparecimento forçado.

A imagem final imagina a personagem-título, se viva, "talvez", lendo mentiras no jornal, que antes já mentia, e os dedos sujos de tinta marcando a xícara branca, "como se transporta/ matéria de matéria/ a matéria, se viva,/ talvez." (Domeneck, 2015, p. 28).

A polissemia da palavra matéria remete tanto às mentiras do jornal (matérias jornalísticas) quanto à tinta, o material, que as imprime e que serve para sujar outra matéria, a louça de que é feita a xícara. Trata-se, porém, de algo que teríamos "se viva" ela estivesse. Como se trata de uma desaparecida, não temos a matéria corporal, tampouco as notícias ou documentos que indicassem onde seu corpo foi escondido, ou como foi executada.

Apesar do tom antimonumentalizante e da sutileza do fim, que se refere ao papel golpista e antidemocrático da grande imprensa brasileira (em 1964 e na ditadura brasileira, mas que pode ser detectado em vários momentos da história, como o passado recente), o poema causou certa celeuma quando publicado no blogue, tendo recebido três comentários negativos em razão da escolha da figura de uma guerrilheira. 
Alexandra Lucas Coelho destacou, no tocante ao livro publicado em 2015, os casos de violência contra as mulheres no Brasil, bem como a criminalização do aborto, e como Domeneck trata deles nos poemas dedicados a mulheres: "Cá está então Maria Bonita, a cangaceira, mulher de Lampião, degolada viva pela polícia. Cá está Ísis Dias de Oliveira (1941-?), título que já diz tudo, nome, data e ponto de interrogação, falando pelos muitos desaparecidos da ditadura militar." (Coelho, 2015).

Com efeito, um dos traços interessantes do poema está na vinculação das questões de gênero à militância contra a ditadura, na escolha da figura de uma mulher guerrilheira:

Os militares, de início, subestimaram a capacidade das mulheres, mas, ao vê-las atuando na luta, inclusive com uso de armas,
tiveram reaçóes de ódio e repúdio. Isso porque as militantes políticas daquela época romperam com preconceitos e barreiras
machistas. Tiveram até que enfrentar a própria organização política de esquerda em que atuavam. A esquerda também tinha
preconceito e as discriminava. Assim, as militantes tiveram que submeter a ordem do estado ditatorial e a ordem interna de
suas organizaçóes políticas. Eram duas vezes subversivas. (Teles, 2017, p. 224)

Como explica Teles, as mulheres de esquerda no Brasil tinham que subverter a ordem patriarcal em suas próprias organizações. É provável que a presença de questões de gênero desde o primeiro livro de Domeneck, Carta aos anfíbios(Domeneck, 2005) tenha predisposto o autor a abordar a encarar a história brasileira sob esse prisma, que é tão necessário, e ainda tão negligenciado.

No entanto, e esta dimensão é perdida na análise de Coelho, Ísis de Oliveira, sob certo ângulo, também desaparece no poema de Domeneck, que trata com surpreendente inespecificidade a trajetória da desaparecida, a tal ponto que o poema poderia ter como título outro nome de desaparecida política no Brasil. Nesse ponto, o poema também se torna, paradoxalmente, uma ação de desaparecimento, não para apagar esta história, mas provavelmente como crítica à luta armada.

A escolha do poeta de não tratar da trajetória militante de Ízis Dias de Oliveira e, em vez disso, tornar o poema a memória do que poderia ter sido, ressalta poeticamente o peso do desaparecimento forçado, um crime de lesa-humanidade, nesta história, e a impunidade, assegurada pelo Estado brasileiro, dos agentes de graves violações de direitos humanos, com a extensão judicial da lei de anistia de 1979 (anistia, etimologicamente, significa esquecimento) aos agentes de graves violações de direitos humanos pelo Supremo Tribunal Federal brasileiro em 2010, contrariando a jurisprudência do Sistema Interamericano de Direitos Humanos, que proíbe as leis de autoanistia (Fernandes, 2010, p. 1687).

Se este poema é uma medida de memória, como o caracterizou a Comissão Nacional da Verdade brasileira, ele o é de forma original: ele representa um testemunho do que não foi, do que poderia ter sido. Há antecessores desse tipo de testemunho na poesia brasileira, como é o caso de Manuel Bandeira (1886-1968), poeta modernista que foi acometido de tuberculose e escreveu alguns poemas que lamentam que seu destino burguês não pôde ser atingido (tornar-se arquiteto, instituir uma família) por causa da doença que, no entanto, não o impediu de alcançar a terceira idade.

Domeneck realiza outra coisa: não exatamente o inventário de uma vida que não pôde realizar-se segundo um destino burguês, como um testamento de Bandeira, mas da suspensão do futuro e do luto imposta pelo desaparecimento forçado.

\section{Eduardo Sterzi e o País que não PREsta}

Sobre Aleijäo, seu segundo livro de poesia, Eduardo Sterzi, respondendo a Leonardo Gandolfi, explicou que sua poesia nascia "da fusão drummondiana de tempo e poeta sob o signo da pobreza", e que o livro fora "concebido desde o princípio como uma espécie de intermitente reflexão poética sobre uma época que me parece singularmente catastrófica, tanto no plano brasileiro quanto no plano mundial”. A esse ponto, aludindo ao famoso poema "O elefante" de Carlos Drummond de Andrade, que alude a um recomeço perpétuo do poeta na escrita, Sterzi acrescentou: "Cada poema deste meu novo livro parece tomar a forma de 
uma tentativa de recomeçar de novo e de novo e de novo... - depois da destruição, sem esquecer a destruição" (Sterzi; Mello; Lima; Gandolfi, 2010).

Trata-se de uma boa chave para o próprio livro. O Aleijão é, principalmente, antitriunfalista e antimonumental: os usos que faz da memória, pessoal e coletiva, assemelham-se a sussurros de subversão como os dos ratos que roem o edifício do século no poema "Edifício esplendor" de Drummond, no livro $A$ rosa do povo.

No início de Aleijão, o poema "Casa de detenção" é dedicado à cidade natal, Porto Alegre, que "acabou": "Persiste a memória do desastre. A noite desova cadáveres neste quarto de outra cidade" (Sterzi, 2009, p.19). Essa assimilação da terra à catástrofe, que pode ser lida de forma um tanto incipiente no seu primeiro livro de poesia, Prosa, ${ }^{3}$ Sterzi a estudaria a partir do antigo topos da terra devastada, retomado por Eliot no século XX, explicando que boa parte dos melhores poetas brasileiros, neste século,

[...] quando dirigem seu olhar ao mundo [...] e aos objetos que os rodeiam [...] se defrontam, quase sempre, com a imagem de uma terra devastada, isto é, de uma paisagem contaminada por uma impotência que é, hoje, coletiva - afinal, nas democracias, o poder soberano, outrora concentrado na figura do rei, está, pelo menos formalmente, com o povo -, mas que eles, inevitavelmente, interpretam como, também, pessoal" (Sterzi, 2014, p. 107).

Outro ponto importante é o tema da violência, que, segundo Fabio Weintraub, não é em Aleijão "um entre outros, constituindo antes o centro de imantação da obra” (Weintraub, 2013, p. 60). Esta sensibilidade para a devastação e para a violência permitiu que ele abordasse de forma bem-sucedida o legado da ditadura militar. O poema "País" responde aos quarenta anos do golpe de 1964. Após o último verso, temos a data "31 de março - 1․ abril 2004". Esse recurso, da data indicar o tema, foi empregado por ele outras vezes, como em "(Plano 100)", a partir do centenário de Carlos Drummond de Andrade, e ressalta o papel da memória nesta poética.

Citamos a primeira parte do poema:

$$
\begin{aligned}
& \text { Isso } \\
& \text { que chamamos "amigos" } \\
& \text { e ds vezes perdemos } \\
& \text { porque o repuxo os carrega } \\
& \text { sempre mais para o fundo: } \\
& \text { para antes das ondas, } \\
& \text { onde morrem os peixes; } \\
& \text { para depois da memória, } \\
& \text { onde morrem duas vezes } \\
& \text { - isso desfaz-se } \\
& \text { sombra } \\
& \text { que a luz } \\
& \text { do farol atravessa }
\end{aligned}
$$

Esse repuxo é pelo menos duplo: são as vagas da memória, onde os mortos submergem e desaparecem mais uma vez (os "amigos"), porém também é dos desaparecidos na ditadura que foram jogados no mar. A prática, que foi comum na Argentina, era conhecida como os "voos da morte" e também ocorreu no Brasil: “[...] era comum o comentário, na Base Aérea de Santa Cruz, acerca do lançamento em alto-mar de cadáveres transportados pelos aviões P-16" (Comissão Nacional da Verdade, 2014, vol. III, p. 602).

Esses amigos desfazem-se no mar: não estão apenas desterrados ou exilados, foram jogados ao para que seus corpos não sejam mais encontrados. A luz do farol é inútil neste contexto: os corpos estão perdidos "onde morrem os peixes", enquanto se desfazem como sombra.

$\mathrm{Na}$ segunda parte, dois versos de uma só palavra também estão recuados, "Isso" e "náufragos": 


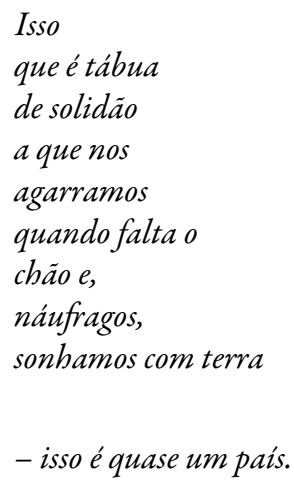

A referência da palavra "isso" é alterada: antes, tratava-se dos corpos que jamais serão encontrados, "amigos" perdidos para o mundo material e para a memória. Poderemos realmente nos lembrar deles? As possibilidades de memória parecem ser o tema da segunda parte: nós, que tentamos recordar os desaparecidos, também somos náufragos e agarramo-nos à memória para não afundar. É terrível ler que essa tábua flutuante, obviamente incapaz de substituir a terra, "é quase um país".

Pode esse frágil substituto para a terra servir de pátria? A memória também não seria antes afirmação do que negação do desastre e do exílio? Eduardo Sterzi não cultiva ilusões sobre eventuais poderes redentores da memória e conclui a segunda parte e o poema de forma implacavelmente lúcida:

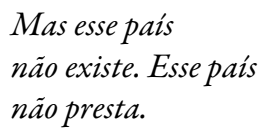

A repetição de "esse país" é bastante eloquente e sublinha o solo que falta a "isso", sua negatividade. A criação de um solo comum talvez seja uma tarefa da poesia, como é um trabalho da língua -mas quanto de desfazer há nessa tarefa. Os melhores momentos de Aleijão, penso, são os de um discurso que tenta afirmar ao (se) desfazer.

Esse trabalho formal é o da arte e difere do texto do historiador. A convergência (para usar uma palavra muriliana) de ambos talvez esteja (creio) no trabalho com as ruínas e os restos, que devem gerar e/ou recuperar discursos, vozes extraviadas de seus autores.

Este poema foi criticado, à maneira de Lukács, "de uma indeterminação niilista, em que situações e figuras carecem de contornos e perde-se a atmosfera de concepção do mundo da obra” (Costa, 2014, p. 48). Discordamos dessa interpretação, pois a não referência de Sterzi a uma personagem determinada, diferentemente da escolha de Domeneck no poema aqui referido, é literariamente expressiva, e produz o efeito de acentuar o caráter coletivo da falta do país e do esquecimento daqueles que se desfazem, desaparecidos. Aqui, o desaparecimento atuou sobre os corpos, os nomes e a memória dos que ficaram sobre a terra - e que também nela não estão firmes: essa terra não é sólida suficiente para formar um país que preste.

As continuidades do autoritarismo, de fato, solaparam a cidadania e impediram a construção de uma cidade comum. Nesse sentido, este poema (e todo o livro Aleijão, na verdade) parece prefigurar a recaída autoritária que o Brasil, que jamais chegou a punir as graves violações de direitos humanos da ditadura militar, sofreu com o golpe de Estado de 2016, que derrubou a presidenta Dilma Rousseff e abriu o caminho para a presidência do capitão reformado Jair Bolsonaro, que tomou posse em 2019.

\section{Paulo Ferraz e Paulo Torres: ready-made, paródia e as reconstruções da MEMÓRIA}

Paulo Ferraz, no livro Vicios de imanência(Ferraz, 2018), reúne poemas dedicados a nomes da poesia brasileira contemporânea, mas também homenagens a mortos políticos (como o operário Manoel Fiel 
Filho), a povos indígenas na América do Sul que foram alvo de políticas genocidas, bem como poemas de "contra-homenagem" aos agentes de graves violações de direitos humanos, da época colonial até o século XXI.

Três agentes de graves violações de direitos humanos listados pela Comissão Nacional da Verdade recebem "poemas contra": o ditador Emílio Garrastazu Médici, o agente infiltrado "cabo Anselmo", o delegado Sérgio Paranhos Fleury, que trabalhou no Departamento de Ordem Política e Social de São Paulo (DOPS/SP), a polícia política.

A própria polícia recebe seu quinhão: o "poema contra o DOPS", "Para não esquecer n. 11" (Ferraz, 2018, pp. 38-39). Neste caso, temos um procedimento interessante de ready-made, pois o poema resulta, na maior parte, de transcrição de documentos do prontuário policial do escritor e militante comunista Paulo Torres ${ }^{4}$. Ferraz apresenta o episódio em que Torres fugiu de um hotel em São Paulo, tendo deixado alguns de seus pertences no quarto. Tratava-se de uma época perigosa para os comunistas brasileiros, entre a repressão à tentativa de revolução em 1935 e o golpe de Estado que Getúlio Vargas daria em 1937. O dono do hotel prestou queixa na polícia, que constatou que se tratava de "um elemento de alta periculosidade". O poema continua com a reprodução da lista dos bens encontrados, que consta em documento do DOPS/SP de 8 de julho de 1936:

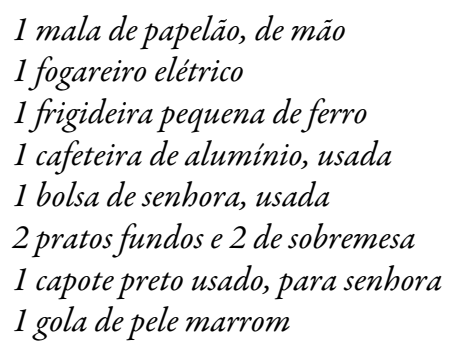

E outros objetos do mesmo tipo, sem caráter revolucionário. O poema prossegue:

O proprietário do hotel, ao realizar as últimas diligências na bolsa, nos bolsos e na gaveta, se deparou com:

exemplares do livro Poemas proletários, não se percebendo, todavia, metáforas, métrica ou rimas que justifiquem chamá-los poemas

folhas mecanografadas do que aparenta ser a obra dramática Andaime, um arranjo sem técnica, sem nenhum merecimento literário, que visa unicamente à propaganda subversiva papel anotado com letra cursiva Antologia dos poetas modernos, Milano (1935), que supomos publicada na Itália jornais velhos que dão pistas de que o Dr. Paulo Torres esteve com bolcheviques em Moscou, cain cativo de revoltosos na Síria e foi dado como morto no Marrocos

Paulo Ferraz deixa aí o ready-made e passa a contar, utilizando a forma policial, fatos da vida de Paulo Torres que, de fato, escreveu o livro e a peça mencionados, que foram criticados como meramente panfletários, embora também tenham sido considerados marcos pioneiros da literatura social no Brasil. Ademais, na década de 1920, ele havia feito aquelas viagens e chegou a ser preso por um bando quando foi encontrar com um chefe rebelde em Marrocos (A Manhã, 1925, p. 1). Em relação à Antologia, ocorre uma zombaria com os conhecimentos literários da polícia política brasileira: trata-se de livro organizado pelo poeta brasileiro Dante Milano e publicado pela Ariel Editora no Rio de Janeiro, e não na cidade de Milão...

O poema prossegue, contando que Paulo Torres não foi encontrado: "Talvez faça versos ou tenha mesmo morrido no Marrocos." Aqui, temos outra ironia de Ferraz, pois Torres sobreviveu àquela viagem e depois dela continuou escrevendo versos. 
O policial despede-se com "Saúde e fraternidade,/ repressão à vadiagem!" e assim termina o poema. Este fecho decorre de um recorte do ofício do delegado Soares Caiuby ao Delegado de Ordem Social, em 8 de julho de 1936, ainda no prontuário de Paulo Torres. Ele assina, como tradicionalmente fazia: "Saude e fraternidade/ O Delegado de Repressão à Vadiagem”. O recorte ironiza a identidade entre fraternidade e repressão, que era vista como medida de "higiene" ou de "saúde" social.

Paulo Torres, como militante comunista que escrevia sobre a vida dos operários, era visto como perigoso para o Estado brasileiro. Nesse contexto histórico, é interessante que Paulo Ferraz ressalte a questão da "vadiagem", que era uma contravenção penal usada para o controle e repressão dos pobres. A militância política, para a polícia, poderia ser classificada de "vadiagem”: a questão social era assunto de polícia.

Paulo Ferraz, ao pesquisar, recuperar e reescrever criticamente documentos históricos da repressão política, emula poeticamente procedimentos de uma comissão da verdade. Um pesquisador desse tipo de comissóes também deve ler criticamente documentos, é claro. No entanto, a literatura é muito mais livre do que os relatórios oficiais e, por isso, Paulo Ferraz pôde no poema assumir sarcasticamente a voz do repressor, o que não seria cabível, tampouco inteligível, para uma Comissão oficial: pensar-se-ia que aquela voz teria sido adotada, e não satirizada.

Esta poética do tipo "comissão da verdade", neste caso, foi empregada para recuperar a memória de um poeta menor, o que pode evocar a poética do escritor e editor argentino Julián Axat, especialmente no livro Ylumynarya, em que trata de "(el día de los muertos o la sociedad de los poetas desaparecidos)" (Axat, 2008, p. 62). No entanto, a forma que privilegia o fragmento, típica de Axat e de tantos autores argentinos da geração, não se verifica no poema de Paulo Ferraz.

Pode-se lembrar da observação de Badagnani sobre a poética dos H.I.J.OS. argentinos, que segue a "estética do fragmento" e prescinde "da ideia de reconstrução de um mapa total"; dessa forma, a "ideia do incompleto ressalta ainda mais o trabalho do arquivista" (Badagnani, 2014, p. 52). Em "Para não esquecer n. 11", o poeta brasileiro preenche as lacunas do documento com dados da história do escritor, obedecendo a uma estética que combina ready-made com paródia.

\section{Desaparecidos, repressão política e as continuidades da ditadura: Priscila Figueiredo e o caso de Rafael Braga Vieira}

No Brasil, em 2013, irromperam diversos protestos contra os poderes instituídos, a começar pela ocupação indígena na Câmara dos Deputados. Em 16 de abril, membros de diversos povos adentraram a Câmara para protestar contra projetos anti-indígenas que tinham como finalidade alterar a Constituição brasileira e acabar com a proteção às terras dos povos originários. Depois dessa ocupação histórica, vieram as chamadas "Jornadas de Junho", com multidões que foram às ruas nos centros urbanos.

Um dos presos políticos dessas Jornadas foi um catador de materiais recicláveis, Rafael Braga Vieira. Curiosamente, ele não participava do protesto, tampouco tinha qualquer militância política. Ele foi preso por estar carregando frascos de água sanitária e de desinfetante, que a polícia entendeu que seriam utilizados para a fabricação coquetéis molotov. Negro e em situação de rua, sua prisão foi considerada "um símbolo do racismo e da seletividade penal contra a juventude negra e periférica no Brasil” (Pina, 2018).

Em 2016, ele foi preso novamente em flagrante, sem testemunhas, de apreensão de menos de dez gramas de drogas. A defesa alegou que o flagrante foi forjado. Em 2017, contraiu tuberculose na prisão e conseguiu, depois de ampla campanha popular, o benefício da prisão domiciliar. A campanha foi necessária porque esse tipo de direito é muitas vezes negado pelo judiciário brasileiro, e a superlotação das prisões, combinada com os deficientes cuidados médicos, leva em geral casos como esse a uma condenação informal à morte.

No episódio de Rafael Braga Vieira, assim como em outros da repressão política em 2013, diversos autores viram continuidades autoritárias da época da ditadura militar. Esse foi um dos casos mencionados no aniversário de 53 anos do golpe de Estado de 1964, em 2017, quando diversas entidades da sociedade civil e 
militantes ${ }^{5}$ firmaram e apresentaram na Faculdade de Direito da Universidade de São Paulo um documento que sintetiza essa posição, o manifesto Onde estão os desaparecidos políticos? Estado de exceção ontem e hoje:

Quase 53 anos depois do golpe de 1964, o Estado brasileiro continua a vigiar e reprimir militantes e manifestantes por direitos tão básicos como a circulação, a saúde, a educação. Continua existindo uma polícia militarizada, contra as recomendações da ONU, da Comissão Nacional da Verdade e de outras Comissões da Verdade, bem como de outros movimentos contra a violência policial e contra o encarceramento em massa e o genocídio da juventude preta, pobre e periférica (Movimentos sociais e organizações da sociedade civil, 2018, p. 529).

Sobre o caso, a poeta e ensaísta Priscila Figueiredo escreveu um poema publicado em dossiê temático sobre memória e justiça de transição da revista InSURgência, da Universidade de Brasília e do Instituto de Pesquisa Direitos e Movimentos Sociais (Figueiredo, 2018, pp. 547-549). O poema imagina a reação da mãe de Rafael Braga ao saber que o filho poderia tratar-se de doença na casa dela. A ideia nasceu de matéria publicada na Revista Piaui(Passos, 2017). A jornalista Juliana Passos informou Adriana Braga, a mãe, que assim reagiu: "Nunca me dizem nada".

Na poesia brasileira, há uma interessante tradição de poemas tirados de notícias jornalísticas; talvez o mais famoso ainda seja o de Manuel Bandeira, que a inaugurou, "Poema tirado de uma notícia de jornal", publicado no livro Libertinagem, de 1930, sobre um suicídio inexplicado. No caso do poema de Priscila Figueiredo, temos as repercussóes privadas de um crime do Estado. Depois da epígrafe com trecho da reportagem, o poema começa:

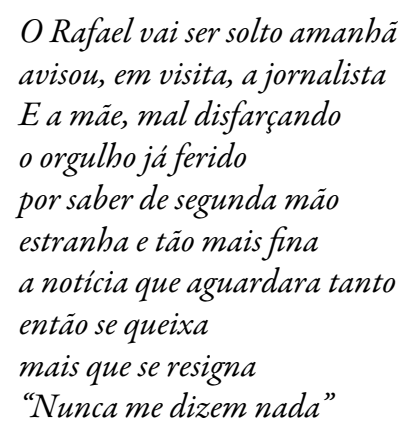

O poema segue incorporando informações da reportagem, mencionando as dores nos rins da mãe. Subitamente, a poeta foge da fonte jornalística:

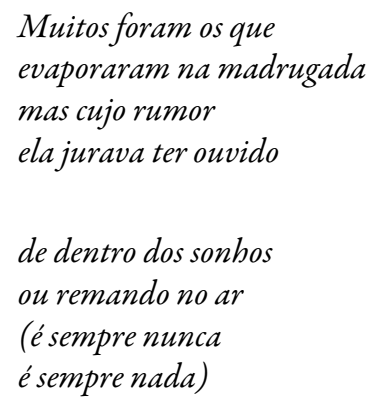

Essa lembrança dos desaparecidos, sobre os quais ficam as imagens do nada de sua presença, e do nunca de seu retorno, irrompe curiosamente neste poema em que mãe e filho, que não estava desaparecido naquele momento, e sim preso por determinação judicial, se reencontram. Quando foi preso pela primeira vez, também não lhe disseram nada, e ela demorou a encontrá-lo.

A situação da mãe que não recebe notícias oficiais do filho, e sim de outras fontes, como a imprensa ou de militantes sociais, não deixa de evocar o que ocorria com os familiares de desaparecidos políticos e continua a ocorrer, visto que diversos corpos de desaparecidos da última ditadura militar no Brasil não foram 
encontrados; também esta medida de justiça transição, a que o Estado brasileiro foi condenado em 2010 pela Comissão Interamericana de Direitos Humanos no caso Gomes Lund e Outros vs. Brasil, não foi cumprida. Por essa razão, a CNV recomendou em seu relatório o "Prosseguimento das atividades voltadas à localização, identificação e entrega aos familiares ou pessoas legitimadas, para sepultamento digno, dos restos mortais dos desaparecidos políticos" (Comissão Nacional da Verdade, 2014, vol. I, p. 974).

Essa conexão entre os crimes do passado e os do presente é realizada, deve-se notar, em sonhos ou na divagação de "remando no ar" (curiosa imagem que pode evocar os desaparecidos que foram jogados de helicópteros pela repressão política), o que parece ressaltar a falta de articulação política entre as vítimas de crimes do Estado na época da ditadura e no presente, após a chamada redemocratização. As iniciativas concretas de aproximação entre os familiares de vítimas do terror do Estado na ditadura e na democracia ainda são muito pontuais.

No poema, os desaparecidos só conseguem irromper como fantasmas no discurso. A chegada concreta do filho, agora cumprindo prisão domiciliar, é retratada seguindo o que a reportagem conta, incluindo a reclamação da mãe em relação ao café e o ano inteiro na prisão. O poema, no entanto, é encerrado com outro interessante afastamento em relação à matéria jornalística:

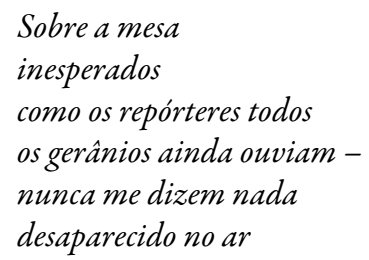

O próprio lamento da mãe submete-se à ordem do desaparecimento. Para sobreviver, não se devem proferir queixas diante dos jornais; as últimas testemunhas são inertes e silentes, as flores que, lemos na reportagem, foram presente de movimentos sociais que defenderam a causa de Rafael Braga Vieira.

Com esta severa limitação da esfera pública, a de fazer desaparecer as próprias queixas das vítimas dos crimes do Estado, termina o poema de Priscila Figueiredo, acentuando mais uma continuidade das graves violações de direitos humanos da ditadura militar.

\section{6. À GUISA DE CONCLUSÃO: POESIA E MEMÓRIA CRÍTICA}

Ana Cecília Olmos estudou a diferença, no âmbito da prosa de ficção do cone sul da América Latina, entre as narrativas dos anos 1980 e 2000, verificando "um potencial crítico que, nos anos de terror, visou desestabilizar o silêncio imposto pelo monopólio da voz do Estado e, nos anos posteriores, objetivou trabalhar pela construção de uma memória crítica do passado imediato.” (Olmos, 2012, p. 133). Para verificar a diferença da construção dessa memória crítica, que não caía na armadilha de um "realismo engajado", a autora tratou de livros de Roberto Bolaño, Martín Kohan, Rafael Courtoise e Luis Gusmán.

Os poetas brasileiros aqui referenciados são exemplos de criação de uma memória crítica que contribui, com suas imagens e discursos, para o processo de criação social da justiça de transição, tão tardio no Brasil em relação a outros Estados da América do Sul.

Dito isso, não se pode verificar neles, ou no corpo da poesia brasileira contemporânea, algo como uma "literatura de hijos" da forma como Emiliano Tavernini a caracterizou na Argentina em sua tese sobre a coleção Los Detectives Salvajes:

Este corpus que hemos reconstruido, entonces, tiene entre sus rasgos: la problematización de la Historia, una apelación política al lector, el sostenimiento de una actitud crítica respecto de las propias condiciones de producción, junto con otras características más formales que hacen a la elaboración de una poética como el uso de la prosopopeya, los anacronismos y montajes temporales, el distanciamiento que proponen ciertas metáforas surrealistas, pero también el haber conformado un 
grupo de asociación laxa que irrumpió en el campo de la poesía con una actitud contrahegemónica. Además, guarda relaciones con dos líneas temáticas que acontecieron al calor del 2001 en la poesía argentina -la de la poesía civil y la de la politización de la institución familiar-y a las que desarrolla. Ambas líneas fueron reinterpretadas y reelaboradas a partir de la experiencia personal e histórica de ser víctimas de la última dictadura militar. (Tavernini, 2018, p. 194)

Em termos formais, estes poemas diferem muito desse quadro, seja pela ausência das metáforas surrealistas (o surrealismo, por sinal, foi pouco influente no Brasil), seja pela questão do apelo político ao leitor. Em termos sociais, não há aqui, realmente, um grupo, seja poético, seja militante. Ademais, não se trata da produção de filhos de mortos ou de desaparecidos.

Domeneck marca-se por uma poesia antimonumentalizante, exercitando a imaginação de futuros que foram vedados pela ditadura a uma mulher guerrilheira desaparecida. Em seu poema, a própria memória da guerrilha é obliterada, e chega-se ao ponto de imaginar a antiga revolucionária participando da amnésia coletiva sobre a ditadura que marca a atual cultura política no Brasil.

Eduardo Sterzi institui uma crítica (no sentido de estabelecimento de limites) da memória social a partir de uma poética que já tratava da devastação e da violência, que são, de fato, prismas privilegiados para tratar da ditadura militar brasileira. Os desaparecidos morreram além da memória e o estabelecimento de uma terra comum, mesmo em sonho, só poderia dar em um país que não presta.

Priscila Figueiredo trabalha, por sua vez, com o esquecimento, mas de forma diferente de Domeneck e Sterzi. Em primeiro lugar, porque ela tem como foco um caso de violência do Estado após a democratização do sistema político; em segundo, porque os crimes da ditadura aparecem como uma lembrança que não consegue se formar, e dessa incapacidade de rememoração a violência do passo extrai sua força e efetividade no presente. Ela vê, dialeticamente, no esquecimento do passado a violência do presente, e na violência do presente a atualidade do passado. A nação talvez se configure, paradoxalmente, no informe da rememoração incompleta dos desaparecidos. A reclamação impotente "Nunca me dizem nada", nesse sentido, pode ser o verso único do hino possível aos cidadãos, e que não será ouvido, salvo por seres inanimados, que não poderão responder ou cantar em conjunto.

Desaparecimento e incerteza ocupam o espaço da ideia de nação, aqui submetida a uma crítica poética bem ancorada na experiência histórica.

Paulo Ferraz recupera a memória por meio de usos do documento histórico, que aparece, no poema selecionado, com o procedimento do ready-made, e, com isso, busca realizar algo como uma "poética de comissão da verdade". Aqui, temos uma poesia de embate contra o esquecimento na tentativa não só de recuperar, mas de ressignificar documentos não poéticos da repressão política. Também para este autor, tratase de não deixar que a última palavra sobre a violência do Estado brasileiro seja dada pelos agentes dos crimes de lesa-humanidade. Uma tarefa mais difícil no momento em que este artigo foi escrito, e em que a presidência da república no Brasil é ocupada por um militar reformado que elogia a ditadura militar e se diz favorável aos crimes de lesa-humanidade.

\section{REFERÊNCIAS}

A Manhã (1925). Paulo Torres entre os drusos. Rio de Janeiro, 23 de março, p. 1.

Abreu, A. Alves de (2009). Instituto Superior de Estudos Brasileiros (ISEB). CPDOC/FGV - Centro de Pesquisa e Documentação de História Contemporânea do Brasil. Recuperado de http://www.fgv.br/cpdoc/acervo/dicion arios/verbete-tematico/instituto-superior-de-estudos-brasileiros-iseb

Atencio, R. J. (2014). Memory's Turn: Reckoning with dictatorship in Brazil. Madison: The University of Wisconsin Press.

Axat, J. (2008). Ylumynarya. City Bell: Libros de la Talita Dorada.

Badagani, A. (2014). Los detectives jacobinos y la poética de los hijos de desaparecidos. Estudios de Teoría Literaria, 3(6), 43-55. Recuperado de https://fh.mdp.edu.ar/revistas/index.php/etl/article/view/962/1016 
Brasil (1967). Decreto-lei 314, de 13 de março de 1967. Define os crimes contra a segurança nacional, a ordem política e social e dá outras providências. Recuperado de http://www.planalto.gov.br/ccivil_03/decreto-lei/1965-1988 /Del0314.htm

Cacaso (1997). Não quero prosa. Vilma Arêas (org.). Campinas: Unicamp; Rio de Janeiro: UFRJ.

Coelho, A. L. (2015). Esta nossa ruína. O Público. Lisboa. Recuperado de https://www.publico.pt/2015/11/08/cul turaipsilon/opiniao/esta-nossa-ruina-1713539

Comissão de Familiares de Mortos e Desaparecidos Políticos, Instituto de Estudos sobre a Violência do Estado (2009). Dossiê Ditadura: Mortos e desaparecidos politicos do Brasil 1964-1985, São Paulo: Imprensa Oficial do Estado de São Paulo.

Comissão Estadual da Verdade Dom Helder Câmara (2017). Relatório final. Recife: Governo do Estado de Pernambuco. Recuperado de http://www.acervocepe.com.br/acervo/arquivos-da-comissao-estadual-da-memo ria-e-da-verdade-dom-helder-camara

Comissão Nacional da Verdade (2014). Relatório. Brasília: Ministério da Justiça. Recuperado de http://cnv.memori asreveladas.gov.br/

Costa, M. A. M. (2014). O sistema literário brasileiro em Aleijão, deEduardo Sterzi. Brasília, Departamento de Teoria Literária e Literaturas do Programa de Pós-Graduação em Literatura, Universidade de Brasília. Dissertação de mestrado em Literatura e Práticas Sociais. Recuperado de https://repositorio.unb.br/bitstream/10482/19770/ 1/2015_MelinaAlvesMeloCosta.pdf

Desarquivando o Brasil (2012). Convocação da 5a Blogagem Coletiva \#desarquivandoBR. Recuperado de https://desa rquivandobr.wordpress.com/2012/03/18/convocacao-da-5a-blogagem-coletiva-desarquivandobr-3/

Domeneck, R. (2005). Carta aos anfibios. Rio de Janeiro: Bem-Te-Vi.

Domeneck, R. (2013). Tal Nitzán traduz para o hebraico meu poema "Ísis Dias de Oliveira (1941 - ?)". Rocirda Demencock. Recuperado de http://ricardo-domeneck.blogspot.com/2013/12/tal-nitzan-traduz-para-o-hebraic o-meu.html

Domeneck, R. (2014). A literatura brasileira sob regimes autoritários. Deutsche Welle. Recuperado de https://www.d w.com/pt-br/a-literatura-brasileira-sob-regimes-autorit\%C3\%A1 rios/a-17534304

Domeneck, R. (2015). Medir com as próprias mãos a febre. Rio de Janeiro: 7 Letras.

Ferraz, P. (2018). Vicios de imanência. São Paulo: Dobradura, Sebastião Grifo.

Escola Superior de Guerra (1959). Introdução ao estudo da guerra revolucionária. Documento reservado. Arquivo Ana Lagôa. Recuperado de http://www.arqanalagoa.ufscar.br/pdf/DocumentosGuerraRevolucionaria/Introdu\%C 3\%A7\%C3\%A3o\%20ao\%20Estudo\%20-\%20C-85-59.pdf

Fernandes, P. (2010). Ditadura militar na América Latina e o Sistema Interamericano de Direitos Humanos: (in)justiça de transição no Brasil e Argentina. XIV Encuentro de Latinoamericanistas Españoles: Congreso internacional, Santiago de Compostela, pp.1674-1692. Recuperado de https://halshs.archives-ouvertes.fr/halsh s-00531273/document

Fernandes, P. (2019). Poéticas da migrância e ditadura: exílio e diáspora nas obras de Julián Fuks e Francisco Maciel. Estudos de Literatura Brasileira Contemporânea, 58, http://dx.doi.org/10.1590/2316-4018585

Figueiredo, E. (2017). A literatura como arquivo da ditadura brasileira. Rio de Janeiro: 7 Letras.

Figueiredo, P. (2018). Nunca me dizem nada. InSURgência: Revista de Direitos e Movimentos Sociais, 4(1), 547-549.

Jiménez, A. (2013). Ferreira Gullar conversa com Ariel Jiménez. Trad. Vera Pereira. São Paulo: CosacNaify.

Hollanda, H. Buarque de (1980). Impressóes de viagem: CPC, vanguarda e desbunde: 1960/70. São Paulo: Editora Brasiliense.

Lovatto, A. (2013). Um Projeto de Revolução Brasileira no Pré-1964: Os Cadernos do Povo Brasileiro. En M. Midori Deadecto y J. Mollier (ed.), Edição e revolução: leituras comunistas no Brasil e na França. São Paulo: Ateliê Editorial, pp. 153-182.

Movimentos sociais e organizações da sociedade civil (2018). InSURgência: Revista de Direitos e Movimentos Sociais, 4(1), pp. 528-536. 
Olmos, A. C. (2012). Narrar na pós-ditadura (ou do potencial crítico das formas estéticas). In: M. Seligmann-Silva, J. Ginzburg, F. F. Hardman (ed.) Escritas da violência. Rio de Janeiro: 7 Letras, vol. II, pp. 133-142.

Passos, J. (2017). Uma mãe à espera: a volta de Rafael Braga à casa. Revista Piauí. Recuperado de https://piaui.folha .uol.com.br/uma-mae-a-espera/

Pina, R. (2018). Símbolo da seletividade penal, caso Rafael Braga completa cinco anos. Brasil De Fato. Recuperado de https://www.brasildefato.com.br/2018/11/22/justica-reduz-pena-de-rafael-braga-e-o-absolve-associacao-ao -trafico

Ridenti, M. (2000). Em busca do povo brasileiro: artistas da revolução, do CPC à era da TV. Rio de Janeiro: Record.

Schwarz, R. (1978). O pai de família e outros estudos. Rio de Janeiro: Paz e Terra.

Sterzi, E. (2001). Prosa. Porto Alegre: Instituto Estadual do Livro.

Sterzi, E. (2009). Aleijão. Rio de Janeiro: 7 Letras.

Sterzi, E. (2014). Terra devastada: persistência de uma imagem. Remate de Males. (34), 95-111, https://doi.org/10.2 0396/remate.v34i1.8635834

Sterzi, E.; Mello, H.; Ferraz; Lima, M. R. de; Gandolfi, L. (2010). A conversa com o dedo aponta para o cadinho menos literário do poema, Fórum de literatura brasileira contemporânea, 2(3). Recuperado de: https://doi.org/10.355 20/flbc.2010.v2n3a17338

Tavernini, E. (2018). Poesía, politica y memoria en la Argentina reciente: La colección Los Detectives Salvajes (2007-2015). Universidad Nacional de La Plata, Tesis para optar por el grado de Magíster en Historia y Memoria. Recuperado de http://sedici.unlp.edu.ar/handle/10915/75218

Teles, M. A. de Almeida (2017). Breve história do feminismo no Brasil e outros ensaios. São Paulo: Alameda.

Weintraub, F. (2013). O tiro, ofreio, o mendigo e o outdoor: representaçôes do espaço urbano na poesia brasileira pós-1990. São Paulo: Faculdade de Filosofia, Letras e Ciências Humanas, Universidade de São Paulo. Tese de Doutorado em Teoria Literária e Literatura Comparada. Recuperado de https://teses.usp.br/teses/disponiveis/8/8151/td e-10022014-102254/pt-br.php

\section{Notas}

1 No decreto-lei 314, de 13 de março de 1967, que definia "os crimes contra a segurança nacional, a ordem política e social", esse conceito era previsto no $\$ 2^{\circ}$ do art. $1^{\circ}$ : "A guerra psicológica adversa é o emprego da propaganda, da contrapropaganda e de ações nos campos político, econômico, psicossocial e militar, com a finalidade de influenciar ou provocar opiniôes, emoções, atitudes e comportamentos de grupos estrangeiros, inimigos, neutros ou amigos, contra a consecução dos objetivos nacionais" (Brasil, 1967).

2 Trata-se de uma campanha de militantes e blogueiros com o objetivo de "abertura dos arquivos secretos da ditadura militar, a investigação dos crimes e violações de direitos humanos cometidos pelo Estado brasileiro contra cidadãos, a localização dos corpos e restos mortais dos desaparecidos políticos, e a revisão da Lei da Anistia para que se possa processar e punir criminalmente os torturadores, além de responsabilizar o próprio Estado pelos crimes de tortura, assassinato e desaparecimento forçado no período entre 1964 e 1979" (Desarquivando o Brasil, 2012).

3 No longo poema "Fuga de Bizâncio", por exemplo, um amálgama de citações e versos próprios, lemos que "todos os tempos" serão um "futuro inexistente" (Sterzi, 2001, p. 72). Significativamente, o poema termina com uma citação do diário de Kafka em que o escritor tcheco assinala, sem o saber, o começo da $1^{a}$ Guerra Mundial

4 Documento sob a guarda do Arquivo Público do Estado de São Paulo (APESP). Acervo DEOPS/SP. Promptuario 796. Paulo Torres.

5 Organizações com atividade voltada principalmente à justiça de transição, como a Comissão de Familiares de Mortos e Desaparecidos Políticos, e o Grupo Tortura Nunca Mais, e também a argentina H.I.J.O.S.-Hijos e Hijas por la Identidad y la Justicia contra el Olvido y el Silencio. Também as organizações que lidam com outras questões ligadas aos direitos humanos, organizaçóes sindicais; cinco partidos políticos a ele aderiram, todos eles de esquerda: o PCB (Partido Comunista Brasileiro), o PCdoB (Partido Comunista do Brasil), o PCR (Partido Comunista Revolucionário), o Psol (Partido Socialismo e Liberdade) e o PT (Partido dos Trabalhadores). 